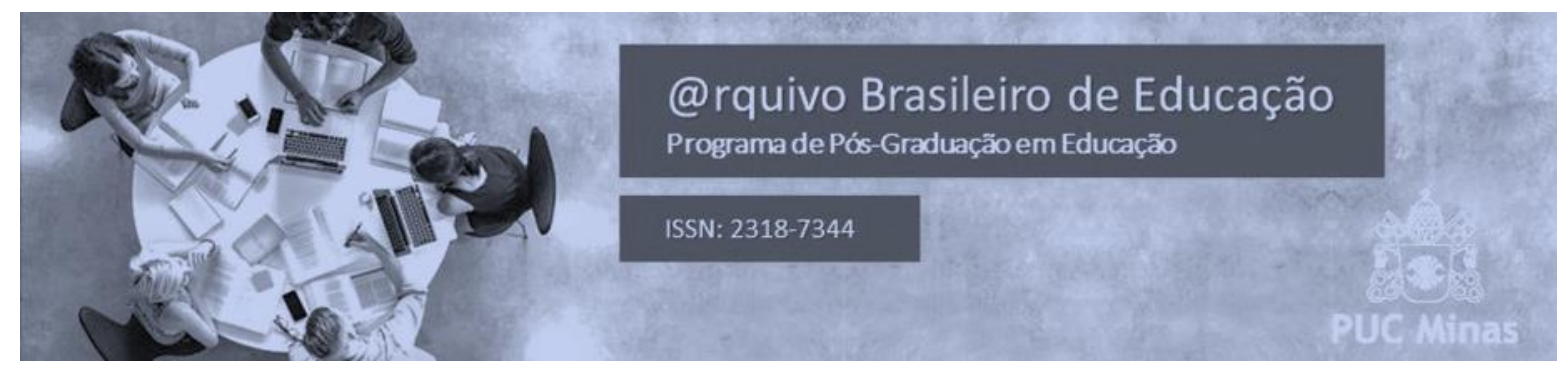

\title{
A CAPOEIRA ENQUANTO CULTURA E PRÁXIS EDUCATIVA
}

\author{
CAPOEIRA AS A CULTURE AND EDUCATIONAL PRACTICES
}

\author{
Alanson Gonçalves \\ RESUMO \\ Pontifícia Universidade Católica de Minas
}

Este artigo fundamentasse em uma análise da capoeira como cultura e práxis educativa, a partir de quatro elementos tomados como fundantes na capoeira que são: corporeidade, musicalidade, ritualidade e ancestralidade. Considerando, estes quatro elementos iniciadores como instâncias formativas, e fontes de conhecimentos, de modo que são realizados como analises transmissoras para alunos novatos e demais participantes, a partir de um estudo comparado entre os estilos de capoeira Angola e Regional. Sendo respectivamente os grupos de capoeira de Belo Horizonte - MG, e de Salvador - BA. Em razão disso, percebemos a magnificência de saberes, e processos de aprendizagem consequentes, que se fazem necessários na formação do capoeirista para construção de sua identidade formativa enquanto "ser no mundo" e a elaboração de pertencimento a uma expressão cultural nacional, com valores civilizadores e tradicionais. Reconhecendo assim, as características fundamentais da capoeira como cultura e práxis educativas contribuitiva, com a discussão entorno da Cultura Afrobrasileira, da Educação e do Patrimônio Cultural Nacional.

Palavras chave: Capoeira. Educação. Cultura. Práxis Educativa.

\begin{abstract}
This article was based on an analysis of capoeira as a culture and educational praxis, based on four elements taken as founding in capoeira: corporeality, musicality, rituality and ancestry. Considering, these four initiating elements as formative instances, and sources of knowledge, so that they are carried out as transmitting analyzes for novice students and other participants, from a comparative study between the styles of capoeira Angola and Regional. Capoeira groups from Belo Horizonte - MG, and Salvador - BA, respectively. As a result, we perceive the magnificence of knowledge, and consequent learning processes, that are necessary in the formation of capoeirista to build their formative identity as "being in the world" and the elaboration of belonging to a national cultural expression, with civilizing values and traditional. Thus recognizing the fundamental characteristics of capoeira as a culture and contributing educational praxis, with the discussion surrounding Afro-Brazilian Culture, Education and National Cultural Heritage.
\end{abstract}

Key-words: Capoeira. Education. Culture. Educational Praxis. 


\section{APRESENTAÇÃo}

Este texto sintetiza a discussão central da dissertação "Práticas e Aprendizagens em Jogo: Um estudo comparado entre a Capoeira Angola - MG e a Capoeira Regional - BA, em diálogo com os saberes escolares”, defendido no programa de Pós-graduação em Educação da PUC-MG no ano de 2012. Estudo, que teve como objetivo, compreender como os saberes e as aprendizagens da capoeira são comunicados aos integrantes e membros de dois grupos de capoeira, o Grupo Iúna de Capoeira Angola, BH - MG, e o grupo Filhos de Bimba de Capoeira Regional de Salvador - BA. Considerasse que as práticas das capoeiras são instâncias formativas e que estão contidos saberes, e aprendizagem que edificam construtivamente, os indivíduos participantes. Incumbimos a capoeira como cultura e uma práxis educativa, a partir de seus elementos iniciadores, que se interligam como bases fundamentais na formação do capoeirista, tais como, sua identidade, relação cultural e social, enquanto (ser no mundo), pertencente a um legado histórico e ancestral, reconhecido como Patrimônio Cultural de Natureza Imaterial pelo Instituto Histórico e Artístico Nacional - IPHAN em 2008 e como Patrimônio da Humanidade pela UESCO em 2014.

\section{A CAPOEIRA E SEUS ELEMENTOS FUNDANTES}

A capoeira enquanto manifestação da cultura afro-brasileira, reúne-se expressamente distintos elementos simbólicos que foram compreendidos e analisados nesta pesquisa, a partir de quatro elementos que determino como instituidores e fundantes: corporeidade; musicalidade; ritualidade e ancestralidade, do mesmo modo, estabelecem e unificam em processos de práticas e aprendizagens constantes na constituição do aprender/apreender a arte da capoeira e do ser capoeirista. Acresce que, tem como base mediadora a oralidade, que dá sentido e direcionamento aos processos de práticas e aprendizagens dentro da capoeira, através do conhecimento dos mestres, contramestres, professores e demais atores culturais.

Primeiramente faço menção a corporeidade, pois através do corpo que a capoeira se materializou e se constituiu. Além disso, através do corpo que o capoeirista se comunica, brinca, dança, luta, por outra, realiza todas estas ações no jogo, que se desdobra, em diálogos corporais constantes. Interlocuções corpóreas exteriorizasse 
por perguntas e respostas que são formuladas pelos movimentos sincrônicos e diacrônicos, através da ginga, golpes, esquivas e mandingas, em repetições e improvisos, movimentos que objetivam enganar, ludibriar o seu camarada, para poder, assim, deferir-lhe uma cabeçada ou lhe derrubar com uma rasteira. Por essa razão, posso aferir que, o jogo é o desdobramento dessa corporeidade dentro da roda de capoeira em junção com seus rituais simbólicos. Eusébio Lobo da Silva (2008), mais conhecido como Mestre Pavão, em seu livro "O Corpo na Capoeira”, o autor nos traz a ideia de um “corpo polissêmico". Neste sentido, nos dá a "ideia de polissemia corporal” como resultado da polissemia da arte da capoeira a partir dos distintos sentidos, em que se pode desdobrar o jogo de capoeira. Para Silva:

\begin{abstract}
Identifica-se, ao proceder um olhar para os conceitos que se desprendem do corpo na capoeira, uma ideia de polissemia corporal, ou seja, manifestações de vários sentidos do corpo - corpo luta, corpo-histórico, corpo-esporte, corpo-dança etc. O capoeirista pode explorar os movimentos da capoeira, que são seus, com diversos companheiros, e descobrir na prática que, no jogo corporal, quando o movimento é a expressão da satisfação interna de uma pessoa e alcança harmonia e beleza, estamos falando da arte da capoeira, seja como sentido de dança, luta, terapia ou qualquer outro. Esses diferentes sentidos são possíveis em razão da característica polissêmica dessa arte. (SILVA, 2008. v. 4, p. 95) ${ }^{1}$
\end{abstract}

Refiro a musicalidade como o segundo elemento fundamental da arte, e do jogo de capoeira, pois é a partir da musicalidade é o seu ritmo, que o capoeirista se expressa, e se manifesta dentro da roda. Necessitamos assim, compreender a musicalidade da capoeira com toda sua complexidade tal como: os tipos de instrumentos que são utilizados na roda; o número de instrumentos musicais que compõem a roda de capoeira; a afinação que estes instrumentos recebem; os ritmos e toques que são realizados; além de compreendermos os tipos de cantigas na roda; e também a "linhagem" da capoeira, ou seja, da sua ancestralidade. Na pesquisa que foi realizada e na comparação entre a Capoeira Angola e a Capoeira Regional, é notória a distinção da formação da roda de capoeira entre um estilo e o outro.

\footnotetext{
${ }^{1}$ Sobre a questão colocada sobre a polissemia corporal na capoeira, compreendo-a, a partir da concepção da capoeira enquanto jogo. Como discutido em GONÇALVES (2012), "a luta, a dança, a competição e a ludicidade, são desdobramentos do jogo de capoeira". Na concepção explorada por Silva (2008, v. 4), considero ser essa "polissemia corporal" do capoeirista, poder lhe favorecer lhe em outras áreas, como no caso do esporte e da dança, uma vez que próprio autor se tornou um exímio dançarino.
} 
Na Capoeira Angola a composição dos instrumentos, denominada pelos angoleiros de "bateria", é constituída por: três berimbaus - gunga, médio e viola; um atabaque; dois pandeiros; um agogô; um reco-reco². Nesta modalidade de capoeira, às músicas cantadas iniciam-se com uma ladainha, passando a uma chula ou louvação, depois a um corrido ou uma quadra, de acordo com o toque e ritmo do berimbau e ritual a ser seguido. Toda via, na Capoeira Regional os instrumentos utilizados não são tão numerosos como na Capoeira Angola, utilizando-se apenas de um berimbau e dois pandeiros, onde a formação da roda é denominada de "charanga" pelos praticantes da Capoeira Regional. Bem como, são cantadas, somente "quadras" e "chulas" na Capoeira Regional. No que concerne à quantidade de instrumentos e aos cânticos, podemos perceber que a Capoeira Angola, é de tal maneira, mais complexa do que a Capoeira Regional. Porém a Capoeira Regional, possui uma complexidade maior referente aos toques e ritmos utilizados dentro de seus rituais cotidianos.

Relativamente, à diversidade musicológica existente dentro da capoeira, não podemos perder de vista as letras das músicas, que são cantadas nas rodas. Letras que retratam a história dos distintos povos africanos vindos da África para o Brasil, do processo de escravidão com seus sofrimentos, conflitos, atos de heroísmos e construção dos quilombos, os mitos e atos de bravura, realizados em guerras ou nos centros urbanos pelos capoeiristas.

\footnotetext{
Sangue Corre na Veia 3

O sangue corre na veia

Na palma de minha mão

O seu nome está gravado

Dentro de meu coração

Dedo de munheca é dedo

Dedo de munheca é mão

Na roda de capoeira

Nunca dei meu golpe em vão

Fecha o corpo camarada

Na Santa Arca do Salomão.
}

Percebemos que às letras das músicas de capoeira são, em sua maioria, narrativas históricas, de acontecimentos e sentimentos vivenciados pelos capoeiristas

\footnotetext{
${ }^{2}$ Sofrendo variações de um grupo ou outro, devido a "linhagem" do mestre de capoeira, podendo variar o número de pandeiros e a ordem em que os instrumentos ficam dispostos na roda.

${ }^{3}$ Música de Domínio Público cantada nas rodas de capoeira. (BOLA SETE, 2001. p. 95)
} 
em seus tempos históricos. Músicas, que carregam consigo, aspectos culturais simbólicos, religiosos, políticos e ideológicos, ou seja, histórias que são guardadas na memória e são repassadas através dos cânticos e da oralidade nas rodas de capoeira. Em sua pesquisa de doutorado “As Musicalidades Das Rodas De Capoeira(s)”, Real (2006) afirma que, estas musicalidades precisam ser compreendidas em uma "perspectiva intercultural”.

\begin{abstract}
As possibilidades das musicalidades das rodas de capoeira serem compreendidas na perspectiva intercultural da educação está em observar as várias visões e diferentes significados, que entram em jogo quando se fala sobre este assunto. Portanto, o diálogo intercultural ocorre quando as diferentes visões de musicalidades, ao invés de anularem umas às outras, são vistas como encontro/confronto de diferentes visões e perspectivas em jogo no universo da capoeira. (REAL, 2006. p. 285)
\end{abstract}

E juntado, como o terceiro elemento a Ritualidade, sua compreensão é de suma importância, para que se tenha um entendimento da capoeira com sua diversidade cultural e seus significados simbólicos, que venha a dar sentido, aos outros elementos. A partir do ritual da capoeira, ou melhor "das capoeiras", que se configuram seus aspectos simbólicos/tradicionais, que vem desde a iniciação do indivíduo no grupo, ou estilo de capoeira, em que se inicia, as músicas e instrumentos que são utilizados na roda, a roupa que utilizam para os treinos e jogos de capoeira, com seus símbolos e cores, até da visão e percepção que passam a ter do mundo. Fator este, que influencia diretamente na forma como estes indivíduos se comportam e se posicionam dentro da sociedade. Podendo ser "angoleiros", "regionais" ou simplesmente capoeiristas com suas identidades culturais constituídas, a partir da iniciação neste novo universo.

São inúmeras, as discussões em torno das identidades culturais, mas meu diálogo aqui, é com o cientista social Stuart Hall, que argumenta sobre as construções e desconstruções históricas das "identidades" a partir da modernidade. Hall expõe, que temos a configuração de uma identidade nacional, a partir da modernidade, e sua desconfiguração a contar do processo de globalização. Com a concepção de "pósmodernidade”, o autor argumenta, que as identidades fixas se tornam identidades moveis, e até mesmo passageiras, ou seja, "tudo que se solidificou desmancharia no ar". Assim como, a ideia da cultura popular, não simplesmente como uma cultura criada do povo, para o povo, e sim, do enfrentamento social e de sua relação contra a opressão 
e a luta pelas desigualdades sociais, na qual a cultura é um elemento crucial dentro do sistema.

\begin{abstract}
A identidade plenamente unificada, completa, segura e coerente é uma fantasia. Ao invés disso, à medida em que os sistemas de significação e representação cultural se multiplicam, somos confrontados por uma multiplicidade desconcertante e cambiante de identidades possíveis, com cada uma das quais poderíamos nos identificar - ao menos temporariamente. (HALL, 2006. p. 13)
\end{abstract}

Dos vários rituais da capoeira, podemos colocar o ritual da roda de capoeira, o jogo em si, como a objetificação de todo aprendizado do ser capoeirista. Porquanto, é no ritual da roda, que o iniciado vai colocar em prática as habilidades, e gestualidades aprendidas, além de deparar com novos desafios, frente aos outros capoeiristas, principalmente aos capoeiristas mais experientes. Sobre a ritualidade e as aprendizagens da roda de capoeira, Abib (2005) explica que:

Em sintonia com essa atmosfera de estímulos sensoriais e mítico-religiosos proporcionados pelo ritual da roda, o aprendizado do iniciante vai se desenvolvendo de modo interativo e profundamente integrado àquela comunidade cultural que passa então a acolhê-lo como um novo membro. (ABIB, 2005. p. 182-183)

Em suma, a ancestralidade é o último elemento a ser analisado. Pela cosmovisão afrobrasileira, a ancestralidade que é percebida enquanto espaço/ritual, representa um elo entre o passado, o presente e o futuro. O jovem iniciado coloca em prática os ensinamentos comunicados pelo seu mestre ou professor, no presente, a continuidade do passado que se preserva em processos de aprendizagens de longa duração 4 . Referente a cosmovisão afrobrasileira Falcão (2004) a descreve como:

A explicitação dessa cosmovisão afro-brasileira na capoeira, além de se apresentar como possibilidade de contraponto simbólico a dominação hegemônica das referências simbólicas européias e norte-americanas, procura fazer coro com algumas bandeiras de lutas defendidas por lideranças respeitadas de alguns setores do movimento negro brasileiro, ideologicamente engajados na afirmação das tradições de matrizes negro-africanas, que buscam possibilidades de fortalecimento dos afrodescendentes contemporâneos no mundo inteiro. (FALCÃO, 2004, p. 147)

\footnotetext{
${ }^{4}$ Me aproprio aqui do termo "longa duração" cunhado pelo historiador francês Fernand Bradeul, por conceber os saberes e conhecimentos da capoeira, como fruto dos processos educativos constituídos a partir das ações realizadas pelos capoeiristas em seus tempos históricos. Constituindo novos conhecimentos em diálogos entre o passado e presente em ações políticas, ideológicas e socioculturais.
} 
A contar da capoeira perspectivamente, com estes quatro elementos fundantes: corporeidade, musicalidade, ritualidade e ancestralidade; somados a transmissão oral são que se constitui o processo de ensino/aprendizagem dos grupos analisados, sendo os mestres e professores de capoeira, a ligação com um passado "remoto".

Considerando assim, os Mestres de Capoeira, como os verdadeiros guardiões dos mistérios, dos saberes e conhecimentos da arte de gingar. Arte na qual o jovem iniciado, objetiva, adquirir um domínio corporal com todas as manhas e malícias 5 do jogo de capoeira, a partir dos distintos ritmos propagados pelo som do berimbau, necessitando ainda, aprender a tocar estes instrumentos, com seus devidos toques, e ritmos. Aprender às músicas, com seus símbolos e significados, para transformar sua compreensão do mundo e de "ser no mundo", preservando e dando continuidade a cultura da capoeira.

\title{
SER CAPOEIRISTA
}

Bem como mostrado, a capoeira na qualidade cultural é percebida aqui, a começar de seus elementos fundantes, tendo sua ancestralidade no processo de uma cosmovisão afro-brasileira, vem reconhecer o legado dos distintos povos africanos e afrodescendentes, que deram significado e origem a capoeiragem, em terras brasileiras, e por conseguinte, um legado que são transmitidos de geração, em geração, dando significados e geradores, alicerçados das experiências, e presença destes indivíduos socialmente.

Presença esta, que se dá, em aponderando-se de uma "significativa importância cognitiva e epistemológica" na vida cotidiana dos indivíduos. E de acordo, com Rocha e Tosta:

\begin{abstract}
Se, por um lado, cultura revela uma concepção teórica sobre a organização, a estrutura e o funcionamento dos sistemas simbólicos e de significados produzidos socialmente, por outro lado também representa um modo de conhecimento, pode-se dizer, um método de pensamento, na medida em que garante a coerência e produz sentido para as ações sociais desenvolvidas no âmbito fenomenológico da vida cotidiana. (ROCHA; TOSTA, 2009, p. 85)
\end{abstract}

\footnotetext{
${ }^{5}$ Os termos, manhas e malicias, são utilizados no jogo de capoeira para designar o capoeirista habilidoso, ardiloso, que com o seu corpo engana o outro de forma manhosa e maliciosa.
} 
A capoeira como cultura afro-brasileira é entendida enquanto "práxis educativa" a partir de estudos, e processos educativos apontados por Paulo Freire, no qual "ensinar não é transferir conhecimento, mas criar possibilidades para a sua produção e reprodução" (2008. p. 22). Compreendo, que os saberes, e os conhecimentos são frutos das vivências e experiências dos indivíduos nas distintas sociedade com suas culturas, consubstanciando-se em práticas, e aprendizagens de ensino, que se desdobram em distintos métodos, ou filosofias de educação. Métodos que são resultados da aquisição de conhecimentos, e saberes, no qual mestres/educadores e discípulos/educandos, aprendem ao apreender, a partir de diálogos constantes que ensejam sobre si, os outros e o mundo. Criando, metodologias de ensino para comunicação de saberes, não sendo esta comunicação, um simples ato de transferência, e no caso da capoeira uma mera reprodução corporal e de sua historicidade. "Pelo contrário, nas condições de verdadeira aprendizagem os educandos vão se transformando em reais sujeitos da construção e da reconstrução do saber ensinado, ao lado do educador, igualmente sujeito do processo." (FREIRE, 2008. p. 26) Neste caso, temos a Capoeira com seus elementos instituidor com objetos e conteúdos mediadores. Sobre o ato de aprender/apreender, Paulo Freire nos oferece uma de suas ricas reflexões e constatações sobre a prática educativa.

\begin{abstract}
A primeira constatação que faço é a de que toda prática educativa implica sempre a existência de sujeitos, aquele ou aquela que ensina e aprende e aquele ou aquela que, em situação de aprendiz, ensina também, a existência do objeto a ser ensinado e aprendido - a ser re-conhecido e conhecido - o conteúdo, afinal. Os métodos com que o sujeito ensinante se aproxima do conteúdo que medeia o educador ou educadora do educando ou educanda. $\mathrm{Na}$ verdade, o conteúdo, por ser objeto congniscível a ser re-conhecido pelo educador ou educadora enquanto ensina ao educando ou educanda, que, por sua vez, só o aprende se o apreende, não pode, por isto mesmo, ser puramente transferido do educador ao educando. Simplesmente no educando depositado pelo educador. (FREIRE, 2011a, p. 109)
\end{abstract}

Conforme expõe Freire (2011a) podemos concluir que a prática educativa só se faz, na relação entre "sujeitos"; sujeitos que ensinam aprendendo, e sujeitos que aprendem ensinando. Neste sentido, posso afirmar que a aprendizagem se consolida com base, em diálogos entre atos e efeitos de educar-se. Processos que se codificam, 
através da comunicação dos saberes, e da reflexão crítica, sobre o que se está sendo comunicado, por que? e para quê? Ensino e aprendizado que são elucidados em um processo dialógico constante a contar do ato gerador ${ }^{6}$ originasse métodos e técnicas de aprendizagens para comunicação dos saberes e conhecimentos objetivados, no qual, a prática e a teoria da prática educativa, se convertam em uma práxis educativa 7. Transformasse os conhecimentos adquiridos na capoeira, não somente em uma mera aplicabilidade prática na roda de capoeira, mas sim, em um processo de conscientização sobre a roda da vida, o jogo cotidiano de luta e resistência na relação do passado com o presente e construção do futuro. "Num pensar dialético, ação e mundo, mundo e ação, estão intimamente solidários. Mas a ação só é humana quando, mais que um puro fazer, é um quefazer, isto é, quando também não se dicotomiza da reflexão." (FREIRE, 2010, p. 44) Um quefazer objetivo e reflexivo que descortina a criticidade e a politicidade da educação, na construção de sujeitos históricos, conscientes de suas ações, seus direitos e deveres. No qual podemos inserir a capoeira na perspectiva da educação não formal que abarcar valores históricos e sociais a partir de uma perspectiva de luta, resistência e tradição.

\begin{abstract}
Esse passado tão presente numa roda de capoeira vigora e denuncia à media que traz à tona tantos conflitos que remetem ao tempo da escravidão, e também de uma violência e opressão exercida contra os marginalizados que, até os dias de hoje, ainda persistem, permitindo dessa foram, uma melhor compreensão do presente, que se traduz como indignação e inconformismo em relação a uma injusta realidade social. (ABIB; In: PARK, 2007. p. 77-78)
\end{abstract}

Barbieri (2003), ao realizar um estudo sobre a escolarização da capoeira, aponta para três visões que estão presentes no fenômeno da Capoeira, quais sejam:

- Uma visão tradicional-popular - que, considerada por alguns, poucos, como ingênua e/ou romântica, concebe-a como uma manifestação cultural cujos fundamentos, oriundos da sabedoria popular, em seu dinamismo, são transmitidos, de geração a geração, no âmbito da relação mestre-aprendiz, considerando, principalmente, as suas perspectivas de luta, dança, defesa pessoal e ginástica, as quais se realizam, respeitando a heterogeneidade de seus participantes, por intermédio do jogo, em

\footnotetext{
${ }^{6}$ Utilizo o termo ato gerador tendo como princípio a proposta dos "Temas Geradores" de Paulo Freire, que ao analisa os conhecimentos e saberes que devam ser comunicados no processo de ensino e aprendizagem a partir de uma crítico-reflexiva sobre o que faz, como se faz, e porque faz, perpassando a mera reprodução.

${ }^{7}$ Refiro-me a práxis educativa, a fim de que o educador leve o educando a reflexão, para que o mesmo adquira consciência de si e do mundo que o cerca. E a partir da autoconsciência, possa se posicionar de forma crítica e reflexiva em prol de sua transformação e na transformação da sociedade de forma concreta e positiva.
} 
momentos de diversão, de ócio, como brinquedo e brincadeira ou nos momentos de busca pela sobrevivência, como arma;

- Uma visão moderno-esportiva - que, surgindo no âmbito da classe média (principalmente entre aqueles simpatizantes e adeptos do militarismo) e alimentada pela pretensão da realização de uma assepsia social e de esterilização das "exóticas" manifestações populares, fundamenta-se nos pressupostos e premissas do chamado Esporte Moderno e, concebendo-a como uma de suas modalidades de luta, preconiza a sua padronização, por intermédio de normas e regras universais "cientificamente" elaboradas, refletindo, assim, os valores e ideais da sociedade burguesa;

- Uma visão existencial-compreensiva - que compreendendo suas manifestações como eventos sinergéticos que refletem e contêm o todo, fundamenta-se no princípio da intersubjetividade e, enfatizando a sua perspectiva de Educação, como o processo de aprender a ser-no-mundo, utilizando-se de uma pedagogia da existência, concebe-a como uma linguagem polissêmica, por intermédio da qual o seu praticante significa a si mesmo, o outro e o mundo. (BARBIERI, 2003, p. 193-195)

Do mesmo modo, que por Barbieri (2003), a capoeira é "um fenômeno que se manifesta, em suas múltiplas perspectivas, permitindo que o ser humano, enquanto corporeidade possa não só lutar, quando necessário, mas também dançar a sua existência" (p.195). E dançando a sua existência este ser, o capoeirista, cria e recria a sua vida no seu devir. A antropóloga Maria Paula Adinofi da $7^{\mathrm{a}}$ Superintendência Regional da Bahia, responsável pela redação do parecer $n^{0}$ 31/o8, "Registro da Capoeira como Patrimônio Cultural do Brasil” descreve que: "A roda é estruturada e o elemento estruturante fundamental da capoeira, mas também tem espaço para o improviso, o inesperado: é a metáfora da roda maior, a roda do mundo, a roda da vida, onde ora se ganha, ora se perde." (Instituto de Patrimônio Histórico e Artístico Nacional; 2008. p. 14).

É nessa roda da vida que se constitui o ser capoeirista, enquanto indivíduo, um cidadão andante, que joga, luta, brinca e canta a sua existência, fazendo de sua arte o seu devir. Por essa razão, necessitamos relembrar que a relação Cultura e Educação estão imbricadas desde os tempos mais remotos, por termos a formação de um "cidadão" passa pelo crivo da cultura na qual se encontra inserido. Sendo, essa cultura, também modificada e transformada pelos indivíduos de tempos em tempos, ganhando novos contornos e significados culturais.

Concomitante ele mesmo, o ser humano, o responsável pela produção cultural e por sua transformação, ou seja, assim como a Cultura e a Educação o próprio é também, inacabado, inconcluso. "Isto é, na inconclusão dos homens e na consciência que dela 
têm. Daí que seja a educação um que fazer permanente. Permanente, na razão da inconclusão dos homens e do devir da realidade.” (FREIRE. 2010, p 83-84). Tal pensamento corrobora também com os argumentos do antropólogo Clifford Geertz:

A grande capacidade de aprendizagem do homem, sua plasticidade, tem sido observada muitas vezes, mas o que é ainda mais crítico é sua extrema dependência de uma espécie de aprendizado: atingir conceitos, a apreensão e a aplicação de sistemas específicos de significados simbólicos. (GEERTZ, 1989, p. 36)

Tanto Paulo Freire, quanto Clifford Geertz compreendem o ser humano enquanto um ser inacabado e inconcluso. Nesse sentido, eis, o ser capoeirista enquanto indivíduo em constante transformação, com seus significados simbólicos e culturais que lhes dão identidades, diferenciando-o dos outros indivíduos dentro da sociedade. O ser capoeirista, que se consolida em tempos e espaços distintos, que são delimitados pela história e pela memória que é gerada, e transmitida através das vivências e experiências, no processo de ensino e aprendizagem. Portanto, a história tem um papel relevante na constituição do ser capoeirista, dado que, por meio da constituição de sua história, e da história de seus ancestrais, que se constitui sua identidade, o que para além de sua experiência e vivência, ele, passara a ser também, o possuidor de conhecimentos ancestrais, que mesmo de forma subjetiva, foram transmitidos pelos seus antepassados. Martin Heidegger realizou uma discussão essencial para compreensão da História e argumenta que:

\footnotetext{
História não significa apenas o "passado" no sentido do que passou, mas também a sua proveniência. O que "tem história" encontra-se inserido num devir. O seu "desenvolvimento" pode ser ora ascensão, ora queda. O que, desse modo, "tem uma história" pode, ao mesmo tempo, "fazer" história. "Fazendo época", determina-se numa "atualização", o "futuro". História significa, aqui, um "conjunto de acontecimentos e influências" que atravessa "passado", "presente" e "futuro". (HEIDEGGER, 2009, p.470)
}

Nesta perspectiva, analiso que o processo de ensino e aprendizagem da capoeira enquanto cultura, se dá, na constituição do ser capoeirista no mundo, que a partir de sua existência, vai criando e recriando novos significados simbólicos que se renovam e dão sentido, a novas formas de ver, ser e estar no mundo. Gerando novos processos de 
ensino e aprendizagem, para que o indivíduo construa sua existência de forma significativa.

\section{CAPOEIRA, CULTURA E PRÁXIS EDUCATIVA}

Em analise a Capoeira como Cultura e "práxis educativa", valido aqui, a Educação em sua perspectiva mais abrangente e em seu conceito mais amplo, como parte do processo histórico e cultural do ser humano, em diálogo com o mundo, a partir de processos e aprendizagens, aquisição e elaboração de conhecimentos. Porquanto, sabemos que ninguém nasce humano e, consequentemente, ninguém nasce sabendo, nos tornamos humanos e aprendemos a apreender, uns com os outros e com o mundo, onde vivenciamos nossa cultura com seus significados simbólicos e culturais, além de os reelaborarmos, produzindo novos conhecimentos e significações. Sendo neste processo de humanização que o homem se torna educando/educador. (GONÇALVES, 2012, p. 78) E tornando-se educando/educador, consegue de forma crítica e reflexiva, unir a prática e a teoria, para o desenvolvimento da práxis educativa.

\footnotetext{
Desse ponto de vista, o bem de produção imprescindível para nossa existência é o Conhecimento, dado que ele, por se constituir em entendimento, averiguação e interpretação sobre a realidade, é o que nos guia como ferramenta central para nela intervir; ao seu lado se coloca a Educação (em suas múltiplas formas), que é o veículo que o transporta para ser produzido e reproduzido. (CORTELLA, 2009, p. 39)
}

Na perspectiva de Cortella (2009) “o mundo construído por nós, o mundo humano, é o nosso lugar”, sendo necessário nos situarmos neste mundo com seus conhecimentos e valores. E que estes conhecimentos e valores são criados por nós, a fim de podermos viver de forma mais coerente e positiva. Cortella explicita que os nossos "valores, conhecimentos e preconceitos mudam porque humanos devem mudar; como vida é processo e processo é mudança, ser humano é ser capaz de ser diferente”. (2009, p. 40)

Podemos compreender que as diferenças humanas estão relacionadas com as distintas culturas existentes e que são resultantes das interações humanas na constituição dos conhecimentos e dos valores culturais. 
Os valores e conhecimentos não têm, evidentemente, existência autônoma: dependem, para realizar-se, de humanos que os elaborem, atribuindo-lhes significados e dando-lhes suporte de manifestação. Ademais, o significado simbólico dessas nossas referências existenciais não é unívoco (do mesmo modo, para todos, sempre) pois é moldado, em termos estruturais, pela Cultural na qual está mergulhado e, por consequência, pela Sociedade e pela história dessa Cultura. (CORTELLA, 2009, p. 40)

A vista disto, compreendo que os conhecimentos e os nossos processos educativos, tanto os de aquisição do conhecimento, tal como os de construção do conhecimento, estão diretamente relacionados com a cultura em que estamos inseridos e a percepção que temos da relação de culturas distintas da nossa. Deste modo, os processos culturais são os responsáveis pela comunicação e constituição da educação em nossa sociedade.

Educação esta, que se encontra de forma inacabada por ser fruto do processo histórico e sociocultural da relação do homem com o mundo. Fato que, de acordo com Rocha e Tosta, este processo, implica que tanto a cultura como a educação podem ser percebidas “a priori, como condição e produto da natureza do homem, de sua capacidade de criar símbolos, significar e ressignificar nos seus processos de interação com o meio e de reflexão sobre si mesmo”. (2009, p. 113).

Podemos concluir, que os processos educativos encontram-se presentes nos distintos tempos e lugares, onde as pessoas se encontram inseridas e se relacionam umas com as outras, sejam elas velhos, adultos, jovens, crianças, homens ou mulheres, dentro das distintas instituições sociais como a família, a escola, o trabalho, os locais de cultos religiosos, a mídia, os centros de lazer entre outros locais não menos relevantes.

Em função disso, posso inferir que onde há relação humana existe educação, e onde há educação existem processos educativos. Pois todo processo educativo é um processo cultural que de acordo com o antropólogo brasileiro Carlos Rodrigues Brandão (2007) “toda a educação é cultura” e:

Toda a teoria da educação é uma dimensão parcelar de alguns sistemas motivados de símbolos e de significados de uma dada cultura, ou do lugar social de um entrecruzamento de culturas. Assim também, qualquer estrutura intencional e agenciada de educação constitui uma entre outras modalidades de articulação de processos de realização de uma cultura, seja ela a de nossos indígenas Tapirapé, a da Grécia dos tempos de Sócrates ou a de Goiânia ou de Chicago de hoje em dia. (BRANDÃO, 2007, p. 139) 
Considero, portanto, o Jogo de Capoeira, como uma manifestação cultural, e consequentemente como um fato da cultura, ou seja, um local com seu tempo e espaço, onde a educação acontece, se aprende e se ensina; um lugar onde os saberes, práticas e aprendizagens estão em constante jogo. E são comunicados de geração em geração, através da oralidade e a partir de seus quatro elementos fundantes que são a corporeidade, a musicalidade, a ritualidade e ancestralidade. A partir das análises feitas e em diálogo com a colega de longas caminhadas, Rosa Margarida de Carvalho Rocha, em seu breve texto "Pedagogia da Diferença" que:

\begin{abstract}
Ao se possibilitar a criação de encruzilhadas, em que possam se entrecruzar dialogicamente as práticas e os valores civilizatórios tradicionais africanos, deseja-se universalizar esses princípios e valores que poderão, certamente, engendrar experiências mais humanizantes e positivas para todos. Assim, nega-se o risco de mudar o foco eurocêntrico da educação para um afrocêntrico. Na verdade, proponho a interação dessas matrizes civilizatórias. (ROCHA, 2009. p. 82-83.)
\end{abstract}

Em suma, no ecoar do berimbau e como em um manhoso e mandingueiro jogo de capoeira, perguntas e respostas vão sendo elaboradas, com o intuito de se compreender a capoeira enquanto cultura e práxis educativa, a partir dos elementos que a constituem e se embrincam na constituição da cultura afro-brasileira, e nas tantas encruzilhadas de formação da sociedade brasileira a efetiva constituição do Ser Capoeirista no carregar o legado histórico de um Patrimônio Cultural Nacional e da Humanidade. Iê... Volta do mundo camará!

\title{
REFERÊNCIAS
}

ABIB, Pedro. Capoeira Angola: cultura popular e o jogo dos saberes na roda. Campinas: UNICAMP, 2005.

ABIB, Pedro Rodolpho Jungers. Capoeira. In: PARK, Margareth Brandini; FERNANDES, Renata Sieiro; CARNICEL, Amarildo. Palavras-chave em educação não-formal. Holambra, SP: Editora Setembro; Campinas, SP: Unicamp/CMU, 2007. p. 77-78.

ARANTES, Valéria Amorim. Educação formal e não-formal: pontos e contrapontos. São Paulo: Summus, 2008. 
BARBIERI, Cesar Augustus Santos. O que a escola faz com o que o povo cria: até a Capoeira entrou na dança. 2003. 379p. Tese (Doutorado em Educação) UFSCar. São Carlos - SP.

BARBIERI, César Augustus. S. O que é Escola? Os seus sentidos da Antiguidade Clássica até os nossos dias. Curitiba: CRV, 2011.

BOAS, Frans. Antropologia Cultural. Org e Trad. Celso Castro. Rio de Janeiro, Ed.: Jorge Zahar, 2004.

BOLA SETE, Mestre. A Capoeira Angola na Bahia. 3. ed. Rio de Janeiro: Pallas, 2001.

BRANDÃO, Carlos Rodrigues. A Educação como Cultura. Campinas - SP: Mercado de Letras, 2007.

CAMPOS, Hélio. Capoeira na escola. Salvador: EDUFBA, 2003.

CHAUI, Marilena. Cidadania Cultural: o direito a cultura. São Paulo: Editora Fundação Perseu Abramo, 2010.

CONDE, Bernardo Velloso. A Arte da Negociação: a Capoeira como Navegação Social. Rio de Janeiro: Novas Ideias, 2007.

CORTELlA, Mario Sergio. A escola e o conhecimento: fundamentos epistemológicos e políticos. 13. ed. rev. ampl. São Paulo: Cortez, 2009.

FALCÃO, José Luiz Cirqueira. O Jogo da Capoeira em Jogo: e a construção da práxis capoeirana. 2004. 393p. Tese (Doutorado em Educação) UFBA, Salvador.

FREIRE, Paulo. Pedagogia da Esperança: Um reencontro com a Pedagogia do Oprimido. 16. Ed. São Paulo, SP: Paz e Terra, 2011a.

FREIRE, Paulo. Pedagogia do Oprimido. Rio de Janeiro: Paz e Terra, 2010.

FREIRE, Paulo. Pedagogia da Autonomia: saberes necessários à prática educativa. 37. ed. São Paulo: Paz e Terra, 2008.

FREIRE, Paulo. Ação Cultural Para a Liberdade: e outros escritos. 12. ed. São Paulo, SP: Paz e Terra, 2007.

GEERTZ, Clinffort. A Interpretação das Culturas. Rio de Janeiro: LTC, 1989.

GOHN, Maria da Glória. Educação não formal e o educador social: atuação no desenvolvimento de projetos sociais. São Paulo: Cortez, 2010.

GONÇALVES, Alanson M. T. Práticas e aprendizagens em jogo: um estudo comparado entre a Capoeira Angola - MG e a Capoeira Regional - BA, em diálogo com 
os saberes escolares. 2012, 176p. Dissertação (Mestrado em Educação) PUC - Minas. Belo Horizonte.

HALL, Stuart. A Identidade Cultural na Pós-Modernindade. Trad. Tomaz Tadeu da Silva, Guaraciara Lopes Louro. 11. ed. Rio de Janeiro: DP\&A, 2006.

HEIDEGGER, Martin. SER e TEMPO. Trad. Márcia Sá Cavalcante Schuback. 4. ed. Petrópolis: Vozes, 2009.

HUIZINGA, Johan. Homo Ludens: o jogo como elemento da cultura. 5. ed. Trad. João Paulo Monteiro. São Paulo: Perspectiva, 2008.

INSTITUTO DE PATRIMÔNIO HISTÓRICO E ARTÍSTICO NACIONAL. Dossiê: Inventário Para Registro e Salvaguarda da Capoeira como Patrimônio Cultural do Brasil. Brasília, dia e mês. 2007. Disponível em:

REAL, Marcio Penna. As Musicalidades Das Rodas de Capoeira(s): Diálogos interculturais, campo e atuação de educadores. 2006. 346p. Tese (Doutorado em Educação) UFSC. Florianópolis.

ROCHA, Gilmar. TOSTA, Sandra Pereira. Antropologia e Educação. Belo Horizonte:

Autêntica, 2009.

ROCHA, Rosa Margarida de Carvalho. Pedagogia da Diferença. Belo Horizonte: Nandyala, 2009.

SILVA, Eusébio Lôbo da. O Corpo na Capoeira: Introdução ao estudo do corpo na capoeira. v. 1. Campinas, SP: UNICAMP, 2008.

SILVA, Eusébio Lôbo da. O Corpo na Capoeira: Breve panorama - estórias e história da capoeira. v. 2. Campinas, SP: UNICAMP, 2008.

SILVA, Eusébio Lôbo da. O Corpo na Capoeira: Fundamentação operacional dos movimentos básicos da capoeira. v. 3. Campinas, SP: UNICAMP, 2008.

SILVA, Eusébio Lôbo da. O Corpo na Capoeira: O corpo em ação na capoeira. v. 4. Campinas, SP: UNICAMP, 2008.

SILVA, Vagner Gonçalves da (Org). Artes do Corpo: Memória afro-brasileira. São Paulo: Selo Negro, 2004.

Sobre o autor

Alanson Gonçalves, Mestre em Educação pela PUC- Minas, Especialista em Maçonologia: História e Filosofia pela UNINTER, Bacharel e Licenciado em História pelo UNI - BH. Conselheiro de Política Cultural do Estado de Minas Gerias - CONSECMG no biênio de 2019/2020, como representante da cadeira de Culturas Afrobrasileiras. Contramestre de capoeira e coordenador do Instituto Cultural Minas Bahia 
de Capoeira - ICMBC, ex-conselheiro Municipal de Políticas Culturais de Belo Horizonte como representante das Culturas Populares e Tradicionais. Experiências na área da Educação com ênfase em Métodos e Técnicas de Ensino, Educação Patrimonial, Jogos e Brincadeiras, cultura africana e afro-brasileira, religiões de matrizes africanas, História da China e Medicina Tradicional Chinesa -MTC. E-mail: alansoncostela@yahoo.com.br 